\title{
Practicing Clinical Bioethics: Reflections from the Bedside
}

Asma Mobin-Uddin

Ohio State University ${ }^{1}$

\begin{abstract}
Biomedical dilemmas are becoming more complex as modern medical technologies continue to advance. In my capacity as a clinical bioethicist, I deal with patients and families confronted by ethical issues and questions that arise during medical treatment. Muslim patients often turn to their faith to help them make medical decisions. In their efforts to avoid what is religiously impermissible, they often ask local imams, community leaders, or Muslim physicians for advice. But these groups typically lack sufficient training when it comes to applying Islamic concepts to the medical dilemmas we face in American hospitals today. In fact, Muslim religious advisors who lack the appropriate medical and religious training should not be giving medical advice. Instead, they should refer their questions to the appropriate scholars, professionals, or referral centers. I have noticed that recommendations received from higher-level Islamic scholars with clinical backgrounds are usually more thoughtful, nuanced, and flexible. Clinicians, patients, and families must be able to access thoughtful Islamic scholarship that supports medical decision making in an accessible, timely, and clinically useful way. By intensifying efforts to combine religious scholarship, clinical understanding, and the effective dissemination of information, those in the field of Islamic bioethics scholarship can better help and support patients and families in determining the most appropriate religiously sanctioned options for their particular circumstances. The American Muslim community must prioritize this field of study.
\end{abstract}

\footnotetext{
${ }^{1}$ Asma Mobin-Uddin, MD, FAAP, is a clinical bioethicist in the Center for Bioethics at the Ohio State University Wexner Medical Center and a pediatrician at Nationwide Children's Hospital, both in Columbus, Ohio.
} 


\section{Introduction}

I still remember the phone call. I did not know the desperate voice on the other end or how she got my number. "Please, you've got to help me. My mother is dying of cancer. Her breathing is getting worse and worse. The doctors are asking if I want to put her on a breathing machine and they have to know right now or she'll die. I don't know what to do."

As we spoke, the caller's mother's ability to breathe was deteriorating rapidly. Her cancer had spread and was affecting her lungs. There was no known cure. The doctors had told the caller that if they put her mother on a ventilator, she would never come off it. The caller did not want to contribute to her mother's suffering by hooking her up to a machine in her final days, but she was also terrified that refusing to do so might violate Islamic teachings. Did Islam's focus on the sanctity and preservation of life mean that she had to extend her mother's life with invasive machinery no matter the circumstances, or were other options religiously acceptable? The caller had no place to turn for advice and she had literally minutes, if not seconds, to decide.

At that time, several years ago, I was a pediatrician who was active in the Muslim community but without any formal training in ethics or Islamic approaches to ethical dilemmas. Muslim physicians are often asked for religious advice to help resolve ethical dilemmas, and often they do not know how to respond. Should they simply say that they are not religious scholars and leave the family with no guidance because doing so is better than giving wrong advice? From whom can they seek urgent answers? Is there any way to bridge the gap between Islamic scholarship and medical practice? One thing is clear: What is happening on the ground today is not meeting the desperate need of patients, families, and medical personnel in addressing the ethical dilemmas common in medicine today.

Since I received that desperate phone call several years ago, I have chosen bioethics, in addition to pediatrics, as my field. After completing a fellowship in clinical bioethics, I joined the faculty at a large academic medical center and began providing clinical ethics consultation services at its associated hospitals while developing ethics educational programs for medical staff statewide. I serve on ethics oversight committees for different hospital systems and am currently pursuing a master's degree in bioethics. 


\section{Bioethics and Clinical Ethics Consultation}

Over the past several decades, clinical bioethics has developed and progressed. This new field addresses an ancient concept in the context of modern medicine: How do we make decisions about what is right and wrong in caring for sick patients? How do we know what is appropriate to do, and who decides? Those who wish to engage with these questions can take different paths to make a contribution. Traditional Islamic scholarship is one way that such questions can be addressed within an Islamic context. In the modern American context, these questions can also be engaged through clinical bioethics, and most specifically as a clinical ethics consultant.

In the modern American context, bioethics refers to an entity that is about 50 years old and encompasses the evolution of a field born and developed in a particular cultural, social, and political milieu. Its development was shaped by many events that converged during the 1960s and '70s. This was a time in which traditional authorities were being questioned and challenged, people were reacting against patriarchal patterns of decision-making in medicine, and there was a growing public awareness amplified by media coverage of unethical practices in research studies. All of these and other factors were mixed with rapid advances in medical technologies that brought to the forefront issues of biomedical dilemmas that previous generations could not have imagined (Eckenwiler \& Cohn, 2007, pp. 6-7).

As a discipline in the medical humanities, bioethics began in the 1960s as a multidisciplinary field, starting mostly out of the interests of university-based scholars and clinicians, with a scholarly focus (Kipnis, 2009; Eckenwiler \& Cohn, 2007, p. 7). The Kennedy Institute of Ethics at Georgetown University was established in 1971 as an institution that would apply moral philosophy and ethical principles to medical dilemmas (Eckenwiler \& Cohn, 2007, p. 5).

In the 1980s, as it became clear that the scholarly focus needed to be supplemented with a practical one, the position of "clinical ethics consultant" emerged. This position drew heavily on bioethics but was practiced in hospitals and had goals, skill sets, and understandings that differed from the academicians' scholarly focus (Kipnis, 2009). Such consultants are specialists who help others sort through conflicts and ambiguities related to values and norms associated with healthcare decision-making as it relates to patient care in a clinical setting, usually a hospital (Kipnis, 2009).

When people ask me what clinical ethics consultants do, I reply that they may be consulted in cases involving medical dilemmas. For example, they might be 
called to assist with questions such as how to proceed with end-of-life decisionmaking, whether to aggressively treat severely compromised newborns, or whether or not curable patients can refuse treatment (Kipnis, 2009). The questions confronting both patients and professionals are complex and becoming more so as the relevant technologies continue to advance and offer new options for diagnosis and treatment. Patients and families facing such situations are extremely emotionally vulnerable, given that stress and distress often accompany such situations and that value-laden concerns and questions are often at the heart of the issues (ASHB Core Competencies For Healthcare Ethics Consultation, $2^{\text {nd }}$ ed., 2011). An ethics consultant's recommendations may result in life and death outcomes, and their memory can affect families for generations.

Clinical bioethics has its roots in, and gains much expertise and knowledge from, disciplines such as philosophy, social services, religious traditions and chaplaincy, legal fields, medicine, and the humanities. Conflicts in bioethics are often the result of foundational differences in philosophy and belief. Religious beliefs, personal mores, values one holds dear, and other similar beliefs are often at the root of an ethical conflict. As such, answers to these questions are often tied to the core of a person's own morality.

The questions we receive are profound, diverse, and fascinating. In many cases, they could not have been imagined in previous times. Some of them highlight differences in values, goals, and beliefs among stakeholders in patient care, whereas others call for conflict mediation because emotions are heightened, the stakes are high, and people disagree on how to proceed.

Some examples of the types of consults that come to our hospital's ethics consultation service follow. Some facts have been altered to protect the patients' identities.

- A previously healthy middle-aged man has received an unexpected diagnosis: He has an inoperable brain tumor and is not expected to live more than six months. Understandably shocked and upset, he has stated that he will not let the brain tumor take him but will instead take matters into his own hands. He is asking to be discharged to his home so he can start putting his affairs in order. His wife is terrified that he might try to harm himself once he leaves the hospital, for he is a gun collector. Should the medical team grant his request once he is medically stable and ready to be released?

- A young mother had infected heart valves due to bacterial contamination following IV drug use. Her infected valves had been surgically replaced 
the previous year. Unfortunately, because she relapsed in therapy and began to reuse IV drugs, the new heart valves also became infected. The only cure is another surgical replacement. The surgeon refuses to perform this operation on the grounds that the patient's continued use of IV drugs will not help provide a long-term cure. However, she has two small children and will die if another surgery is not performed. What should the medical team do?

- The hospital's labor and delivery unit calls late at night. A 17-year-old patient is in labor and has shown poor pain tolerance during initial exams. Because she is legally a minor, the medical team reached out to her mother to obtain consent to administer pain medications, including epidural anesthesia, if requested at any time by the patient. The mother refuses to give consent, saying that in her culture women do not take pain medicines during labor and that her daughter should follow this custom. The medical team is distressed because they feel that the views of the patient should be respected and that it is cruel to deny her possible request because her mother holds different beliefs. Who should make the decision about accepting pain medication during a difficult labor, and how does the patient's mother being the legal decision-maker for the patient affect this situation?

These and other questions can seem overwhelming. How can one possibly know what the "right" thing to do is? And how does one approach these questions in light of the fact that we live and practice in a pluralistic society, which means that our patients, families, the medical staff, and the ethics consultants themselves may all have different religious, philosophical, cultural, and/or other beliefs and values?

One Qur'anic verse that influences me greatly in my work is "Wa laqad karamnā Ban̄ Adam" ("And We have certainly honored the Children of Adam"2) (17:70) In this intimate and profound verse, Allah (swt) ${ }^{3}$ is emphasizing to me that He Himself has honored and dignified the Children of Adam. I reflect that Allah did not say that He has honored and dignified the believing Children of

\footnotetext{
${ }^{2}$ The Qur'an uses Bani Adam (Children of Adam) to refer to the descendants of Adam [and Eve], namely, humanity.

${ }^{3}$ This stands for subhānahu wa ta 'ālā (glory be to Him, the Most High), a glorification used after the name of God.
} 
Adam, the Muslim Children of Adam, or the Children of Adam who have never made choices that compromise His instructions. I am reminded that God instructs me to interact with each person, fully cognizant of the immense value and worth that He has placed in each human being. The Qur'anic verses that call for us to stand firm for justice as witnesses before God and Prophet Muhammad's ( $\mathrm{saw}^{4}$ ) patience, kindness, and love for humanity also inspire me and guide my work ethic.

\section{Ethics Consults Involving Muslim Patients}

The vast majority of the ethics consults we do in our hospital do not involve Muslim patients. For the consults that are related to Muslims, however, I have noted some recurring themes. Observant Muslims tend to want to use their faith to help them make medical decisions and they want to avoid that which is religiously impermissible. When complex medical decision-making is needed, they may feel that they do not have adequate support and knowledge from religious sources, and often they do not know where to turn for help. It is especially challenging for them to know how to find reliable answers quickly, as their medical situation may require an urgent decision.

Muslims may seek advice on medical ethics questions from their local imams or community leaders, who usually have no clinical training, or from Muslim physicians, who usually do not have training in Islamic approaches to medical decision-making. Both groups of advisors mean well but are often acting on feelings and vague understandings of religious beliefs and themes. In my experience, both groups usually lack sufficient training when it comes to applying Islamic concepts to the medical dilemmas we face in American hospitals today.

The result is often rigid advice given without engagement, attention to context, or understanding of the clinical situation. I have often seen religious advice given by first-line religious resources actually make the situation much worse, causing more suffering, increased moral distress, and sometimes even chaos.

I would like to share a few examples in which ethics consults were placed by the hospital medical teams questioning if they were doing the right thing due to the distress or dilemmas relating to Muslim patients and the religious advice they had received.

\footnotetext{
${ }^{4}$ This stands for șallā Allāhu 'alayhi wa sallam (may God's blessings and peace be upon him), a traditional prayer said after mentioning the Prophet Muhammad's name.
} 
One patient was a frail, elderly Muslim man with end-stage cancer for whom there were no more treatment options. When I went to see him, he was alone in his room, deep in thought and distress. Even though he was not the one who had called for the ethics consult, he recognized that I was Muslim, seemed relieved to see me, and shared his struggles. He told me that he was wrestling with a particular question: If he committed suicide, would he still be able to have a janāza prayer and be buried in a Muslim cemetery? He was close to dying, with a terminal illness and a failed heart. He had been put on a Left Ventricular Assist Device (LVAD), a surgically implanted pump that helps his failing left ventricle pump blood throughout his body. Basically, this machine was doing the work of his heart. But now that the pump had taken over his heart's function, it would stop functioning only if the machine was turned off.

There was no cure for his illness, his condition was deteriorating, and the doctors had recommended that he go home with hospice support to focus on endof-life care and comfort management. The patient now felt that the burdens of the medical interventions and treatments were greater than their benefits, and he wanted to act on their recommendation. The hospice providers had indicated that before they could accept him, some kind of plan needed to be in place for turning off the LVAD when the time to do so came.

When the patient asked his imam if it was permissible to turn off the LVAD or to make a plan for doing so, the imam replied that doing so would be tantamount to committing suicide and was not allowed under any circumstance. Weak from his illness, he softly voiced his distress to me. He was so tired and wanted to be done with the ineffective treatments. He wanted to have a janazza and be buried in a Muslim cemetery after his illness took him. He was not sure if he was allowed to go on hospice care. He felt that the only way to get the medical care he needed was to make a choice he believed would be committing suicide, which might deprive him of Islamic burial rites, incur a major sin, and have negative consequences in the hereafter. He did not know what to do.

This man could have benefited from compassionate and scholarly religious advice on so many issues. The first one was the reassurance that he could have a janāza and be buried in a Muslim cemetery regardless of whether he accepted or refused further treatment. And as clear cut as the imam's advice seemed to this patient, the opinions on this question are varied and allow for more religiously sanctioned options than he was led to believe. The advice he received resulted in great distress and a false understanding of other options and their consequences. These were the agonies with which he was struggling when I saw him that night, and he carried the burden of his thoughts and fears pretty much alone during his time of need. 
Another case that has stayed with me involved an ethics consult placed by a medical team to help them resolve a question of medical futility.

The patient was a Muslim woman who had had an anoxic brain injury that was believed to have permanently damaged her brain due to lack of oxygen when her heart had stopped. Her kidneys had stopped working and she was on dialysis permanently. Her lungs had failed, and so she had a tracheostomy tube in her neck connected to a ventilator on which she was dependent for her ability to breathe. Her family knew that her brain would not recover, per medical understanding. She had no brainstem reflexes and did not withdraw from painful stimuli. The family knew and accepted that she would have no meaningful neurological recovery, which meant she would never wake up, be able to communicate, be aware of what was happening around her, or be able to breathe on her own.

The family told the medical team that it was their Islamic religious obligation to continue all aggressive medical care because as only God could decide when she would die, they had no right to make any decisions or limit any therapies that might result in her death. Although the patient's young adult son was the legal surrogate decision-maker according to state law, he obviously was not the family's accepted decision-maker, for before making any decisions he regularly consulted his maternal uncle in Saudi Arabia.

This relative had never seen his sister in her current state and had never spoken with her physicians, despite their multiple offers to do so via interpreters. He had, however, asked a sheikh in Mecca if it was allowed to disconnect any life support equipment. The sheikh had told him that doing so was absolutely forbidden regardless of the circumstances and that they would be guilty of murder and incur the resulting sin if they allowed the current treatments to be stopped.

The patient's body and organs were slowly shutting down, despite maximal medical support from machines and medicines. The medical team, especially the bedside nursing staff, expressed their profound moral distress at being ordered to continue the aggressive and painful medical interventions. They perceived these actions as making them impose suffering on the patient in her final days, instead of allowing her a natural death in peace and comfort.

Because the family cited Islamic requirements to justify their decisions, we consulted, with the son's permission, internationally respected Muslim scholars with expertise in Islam and medicine, including high-level jurists trained at alAzhar, who offered to speak with the family. These scholars were clear that if there was no chance of recovery, then there was no Islamic obligation to continue treatment. They also said that "the family may withdraw treatment, and it will not 
be as if they are ending the patient's life." But ultimately, they noted, it was the family's decision.

The son indicated that he was aware that there were differences of opinion among Muslim scholars in such cases, but that he did not want to be responsible for taking actions that he believed would cause his mother's death. The uncle in Mecca refused all of the scholars' offers to discuss the situation by phone.

One of the main issues of concern to me in these cases was not simply that a family might choose to continue aggressive care when there was no chance of recovery, but that they felt obliged to do so due to the religious advice they received in the name of Islam. They felt that they had no choice, despite what they might have felt at the bedside or their doctors' recommendations.

That was an injustice to the patient and family, and it resulted in great suffering. If the patient and family had known that they had other religiously acceptable options that would not be considered a sin, they could have worked with their doctors to make a decision that was appropriate for them and honored their loved one, instead of deferring to a false understanding of an Islamic legal maxim.

\section{Thinking through the Case of Charlie Gard: Insights from the Process}

To give more insight into the experience that Muslim patients and families might have when trying to get advice from Islamic resources about ethical dilemmas, I would like to share my experience preparing for an interfaith panel discussing the case of Charlie Gard. Last year, I had the opportunity to present at the Conference on Medicine and Religion, alongside Christian and Jewish colleagues representing their faith traditions, to give an Islamic perspective on the ethical issues surrounding this case.

A British infant named Charlie Gard had an incurable, rare genetic mitochondrial disorder that led to him experiencing progressive, irreversible brain damage and muscle dysfunction. In the summer of 2017, at age 11 months, he required permanent mechanical ventilation. His physicians wanted to change him to palliative care and advised the family to withdraw aggressive medical therapy, which the physicians considered to be too burdensome and not in the infant's best interest. When Charlie's parents refused, the hospital took the case to court. After several steps in the legal process, the British courts ruled in the hospital's favor and ordered the withdrawal of his life support treatment.

This case generated a lot of international media interest and discussion about the bioethical issues involved, including who has authority in end-of-life decision- 
making for a terminally ill, neurologically devastated child and if the medical establishment should have the moral and legal authority to withdraw life support measures against the parents' wishes.

I based my approach on looking at the situation from a Muslim parent's perspective, instead of initially going to the most learned Muslim scholars. What if Muslim American parents were faced with having a child with the same diagnosis? How might they try to find religiously sanctioned advice in an American context, and what religious advice were they likely to be given?

Parents would likely first do an internet search to see if they could find any relevant religious rulings. From my experience, they would then approach their local imam, a trusted community leader or elder, or a Muslim physician for advice. A limited number of families might have connections with higher-level Islamic scholars.

In order to re-create the path that the parents might take, I first did an internet search and then interviewed resources to see what type of Islamically based advice the family might receive. My internet search failed to find any mention of Islamic scholars discussing the case of Charlie Gard. I discussed ethical questions related to the case with a community elder who is also the president of a local mosque, gives sermons, and does informal counseling with community members, as well as with a Muslim physician who is actively involved in the field of Islamic bioethics. I then interviewed two imams, both of whom have had several years of formal study to become imams, have extensive experience as Muslim religious leaders in America, and are currently employed as imams at large mosques in the United States. Finally, I interviewed a national scholar who is a permanent member of the fatwa committee of a well-respected and established Islamic jurisprudence council and who is a practicing physician.

Table 1 lists the responses from each resource in answer to the question: Is it Islamically acceptable to withdraw aggressive treatment per the doctor's wishes for the goal of avoiding prolonging Charlie's suffering? 
Table 1. Answers to the question: Is it Islamically acceptable to withdraw aggressive treatment per the doctor's wishes for the goal of avoiding prolonging Charlie's suffering?

\begin{tabular}{|c|c|c|}
\hline$\underline{\text { Source }}$ & Answer & $\underline{\text { Clarifications }}$ \\
\hline Community elder & No & $\begin{array}{l}\text { - "Life is far more important } \\
\text { than the potential for struggle } \\
\text { or hardship" } \\
\text { - Also the doctors could be } \\
\text { wrong about the potential for } \\
\text { improvement }\end{array}$ \\
\hline Muslim physician & Not until... & $\begin{array}{l}\text { absolutely every avenue to save } \\
\text { his life has been exhausted }\end{array}$ \\
\hline Imam 1 & It could be if... & $\begin{array}{l}\text { the body of scholars or the group } \\
\text { of parents, Muslim doctor, and } \\
\text { council of Muslim scholars agree }\end{array}$ \\
\hline Imam 2 & Yes & \\
\hline $\begin{array}{l}\text { Jurisprudence/Fiqh } \\
\text { Council scholar, also } \\
\text { a physician }\end{array}$ & Yes & $\begin{array}{l}\text { If the child is suffering and in pain } \\
\text { and the doctors think that it is } \\
\text { completely hopeless }\end{array}$ \\
\hline
\end{tabular}

In response to the question about the Islamic acceptability of withdrawing aggressive medical treatment to avoid the infant's suffering, the Muslim religious advisors I consulted had vastly different answers. The community elder stated that preserving life is at the core of Islam and that "life is far more important than the potential for struggle or hardship." He noted that Islamically, an involuntary hardship in this life is viewed as a mercy from Allah, the Most Merciful, because it translates into forgiveness of sins and elevation in the ranks of heaven in the hereafter. He also wanted the parents to know that Islam does not consider conditions "untreatable," because God has created the cure for whatever ailments exist. For all of these reasons, he said that it was not Islamically permissible to withdraw support to prevent the child's suffering. 
On the other end of the spectrum, the figh council scholar said that if the patient does not feel or see anything or act willfully (no 'ilm or irädah, he said), then the majority of Muslim scholars say that intervention would not be needed. He said this state lacks the basic qualities of life - to feel and to respond. In other words, no intervention is required if a person is in a vegetative state, provided that there is no hope that he or she will come out of it. However, intervention in such cases is not prohibited.

One thing that struck me while researching my panel presentation was the stark differences in approach between what the typical first-line advisors would usually tell the patients and their families and what the clinically trained, highlevel religious scholars would recommend. Both in my preparation and in my clinical experience, the former usually included community elders and imams, neither of whom had been clinically trained, and medical doctors who were not religious scholars. In the vast majority of cases, both groups believed that Islam's stance on the sacredness of life meant that a patient had to "do everything" and could not refuse or discontinue medical treatment under any circumstances. Some even said that doing so was suicide (if the patient made this choice) or homicide (if the family made the choice on behalf of a patient who is not able to make decisions) and that the patient/family would incur the resulting sin.

This also translated into not allowing any discussion of withdrawing support, regardless of the clinical circumstances and whether or not the patient has or is expected to regain consciousness. Some stated that Muslims cannot be on hospice or have a do-not-resuscitate (DNR) order. "God can perform a miracle, and you can't give up hope, you have to do everything," was the prevailing theme among most of the people I interviewed who would most likely represent the religious advisors to whom a Muslim family would first turn to for advice.

However, as I spoke with higher-level Islamic scholars, especially those who served on fiqh councils and had clinical training, I was very surprised to hear what amounted to a 180-degree difference in terms of the advice being given. This group's responses were thoughtful, more nuanced, and allowed for much more flexibility. Moreover, they usually offered a range of Islamically acceptable options and were much less rigid in their approaches.

I expressed my surprise to the main national fiqh council scholar I interviewed: Dr. Hatem Al-Haj. Dr. Al-Haj is a member of the Permanent Fatwa Committee of the Assembly of Muslim Jurists in America (AMJA), a body of scholars of Islamic law that focuses on issues pertaining to Muslim minorities in the West. He is also a practicing physician in the United States and is board certified in pediatrics. 
I asked Dr. Al-Haj why, in most of my years of clinical experience, the imams and Muslim religious advisors to whom my patients have turned at the bedside have most commonly held very rigid beliefs and felt that it was an Islamic obligation for patients to continue aggressive medical therapy and life support regardless of the situation. This scholar and physician acknowledged that this happens, and he felt this was due to the fact that people and even imams are often not well-versed in knowledge or Islamic scholarship, which affects their decisionmaking advice. He indicated that the religious leaders may be reacting on a gut or an emotional level based on feelings, but that their views are not grounded in appropriate Islamic scholarship. Perhaps, he suggested, they feel that life is sacred and thus must be maintained in any situation.

Dr. Al-Haj thought that the advice I am describing is not backed up by traditional Islamic jurisprudence and is also not the view of the majority of modern Muslim scholars. He clarified Muslim scholars' views on medical treatment, both in classical fiqh and in contemporary Islamic law, citing work with the International Islamic Fiqh Organization, which is part of the OIC (the Organization of Islamic Cooperation).

Dr. Al-Haj said that in classical fiqh, seeking medical treatment has never been considered to be a general obligation in any of the four major Sunni schools of thought. At best, it has been considered recommended by some and sometimes obligatory in certain specific circumstances (e.g., emergency situations or when contagious diseases threaten societal health and safety). He then stated that contemporary scholars' views have changed, perhaps due to the more effective nature of medical treatments today, such that some of them are warming up to the concept of obligatory treatment.

However, he clarified that even with regard to contemporary Islamic scholarship, accepting medical treatment would only be considered obligatory if certain conditions are met, among them that the disease is harmful, the medication is curative, the medication is safe, and the burden of the medical treatment is not worse than the disease itself. Thus, medical treatment is not required for an incurable disease. Being supported by a ventilator or using a feeding tube is included in medical intervention, and therefore required only if the patient's condition is curable, according to the majority of Islamic scholars, as relayed by Dr. Al-Haj.

If there is any ambiguity about the possible outcome, then one should side with hope. However, he emphasized that it must be a "reasonable" hope based on current scientific knowledge. As to whether a patient has to continue treatment because God could perform a miracle, Dr. Al-Haj answered: "Medical 
intervention needs to be based on the knowledge of the doctors, not on the knowledge of God... If God wants to override the decision with a miracle, He doesn't need our help with this."

\section{Current Challenges and Needs in Islamic Bioethics Scholarship within an American Muslim Context}

I recently attended a conference in the United States on Islamic bioethics that brought together Muslim scholars, researchers, clinicians, and other experts from around the world to discuss bioethical issues. During this ambitious and much appreciated effort to get Muslims from different fields of expertise in the same room to connect, learn from each other, and tackle issues related to bioethical concerns, I was again surprised at the large disconnect between Muslim scholars and Muslim medical professionals currently engaged in clinical work.

Many clinical questions were directly asked of scholars throughout the conference; however, most of the answers given to these clinical questions did not provide practical, on-the-ground support to medical professionals desperate to know how to proceed when they are with their patients. Many times, specific clinical questions were deflected or avoided. Other times, the answer given was simply that additional study was needed, and it was even suggested that training future scholars and students over the coming years and decades would address the questions. Clearly, many of the scholars did not grasp that clinicians who grapple with these issues every day need help immediately.

To me, this was shocking and extremely disheartening. If one could not receive clinical guidance at this type of conference, where could one turn?

I appreciate that clinical questions are challenging and that scholars want to give thoughtful, researched answers only after careful study. It is understandable and commendable that they want to avoid succumbing to pressure for a quick response that they might later regret. The vast majority of religious scholars have no clinical background or medical training, and many of the issues they face have no precedent in Islamic law or previous cases. Yes, the challenges are vast and great, but knowing that they exist should encourage us to come up with creative solutions instead of paralyzing us.

I hope that my perspectives on the scope of the problem have not been skewed because of the patient population I see, for ethics consults are only called for the most challenging cases, which usually involve moral distress and conflict. Perhaps the overall view is not as bleak and I am just not seeing the larger picture in perspective. I hope that this is the case. However, the more I talk with people, 
the more I am convinced that in too many cases Muslim patients are receiving, in the name of Islam, completely inappropriate advice that is not based on sound Islamic scholarship - a great injustice that is leading to immense suffering.

I once heard a very influential imam state at a national conference that he did not know what hospice was, but that as Muslims we could not accept it. Since when is it acceptable in Islamic scholarship to give a directive about something that you have not taken the time to understand? I recently interviewed a Muslim physician who had just given a national talk on Islamic bioethics. He told me that if a Muslim patient refuses the surgical placement of a feeding tube, even if he or she is in the end stages of dying due to a terminal illness, this amounts to committing suicide.

I find this type of statement completely unacceptable on many levels. According to Dr. Al-Haj, such a statement is a complete betrayal of Islam's classical teachings. The medical literature is clear that artificial nutrition and hydration can potentially cause harm by resulting in medical complications and increased suffering for patients near the end of life, while it is unlikely to prolong life in this situation (American Academy of Hospice and Palliative Medicine Statement on Artificial Nutrition and Hydration Near the End of Life, 2013). We should not be burdening families and patients struggling with complex medical decisions with inappropriate comparisons that increase their grief and distress and are a travesty with regards to our scholarly tradition.

I asked Dr. Al-Haj why some people make such statements. He replied that some scholars view ventilators and feeding tubes not as medical interventions, but as a way to deliver air, food, and water. As these should not be withheld from a patient, they feel that the delivery of such items should not be restricted either. This view has led to the belief that a patient cannot refuse to be placed on a ventilator or have a feeding tube inserted. Dr. Al-Haj stated that in his view, as well as in the views of many other scholars, ventilators and feeding tubes are clearly not just deliverers of air or food, but instead are complex medical interventions. As such, he feels that patients and their families have the right to refuse them if the burdens of their use outweigh the benefits.

Patients and families need to be aware of existing differences in Islamic opinions on medical issues and that there may be more Islamically sanctioned options than people are being led to believe. Religious advisors who have no clinical training and/or religious scholarship in this area should not be giving medical advice. Instead, they should refer their questions to appropriate scholars, professionals, or referral centers. If they wish to engage with such questions to 
meet the need in their communities, then they should get appropriate religious and clinical training.

We can no longer remain complacent about accepting well-meaning but misguided people giving downright dangerous religious and medical advice in the name of Islam. This sloppy approach causes harm that can last for generations, as the accompanying emotional toll, draining of financial resources, and spiritual guilt takes their toll on both the patients and their families. We have to do better.

I do not mean to be dismissive of the scholarship that is currently being conducted on biomedical issues in the American Muslim context. Instead, I would like for scholars to hear my plea that the work being done is not reaching the patients' bedsides and that the ensuing lack of guidance is causing desperation and great suffering.

\section{Suggestions for a Path Forward}

We have to start approaching biomedical dilemmas with more urgency and attention to clinical practicality. We have to develop ways for clinicians, patients, and families to access thoughtful Islamic scholarship. We have to develop means of support for biomedical dilemmas that are accessible, timely, and clinically useful in American hospitals today. Our resources must be strongly grounded in the Islamic tradition while being responsive, adaptable, and nimble. Technology is changing rapidly, and our scholarship needs to adapt to the pace at which our world is moving.

As specialized knowledge is needed, we should build upon the current process of bringing together the expertise of Islamic scholars and the clinical knowledge of medical professionals so that they can address bioethical issues together. But we need to bring them together with a greater urgency, more open channels of communication, better networking, and more discussion. We also need to empower both groups to be more effective and comfortable when dealing with bioethical dilemmas.

This can be done in many ways. For example, the more connections that Islamic scholars have with clinical medicine, the better they will understand the context in which clinicians make decisions and the effects that these decisions have. Interested scholars can increase their clinical awareness in various ways, such as by participating in programs arranged through a hospital's pastoral care or chaplaincy department, volunteering at health care facilities, or serving on their local hospital's ethics committee. Many hospitals welcome diversity of thought in their ethics committees and often include both local clergy from different faiths as 
well as community members at large. Scholars who understand the culture and environment in American hospitals are greatly needed, for they can offer contextually appropriate recommendations.

Scholars are doing a lot of work on bioethical issues; however, it is often neither accessible nor searchable by Muslim medical professionals or community members. Attention to improving access to and the dissemination of educational materials about common ethical dilemmas would help the community greatly.

Many Muslim healthcare professionals want to increase their understanding of Islamic bioethical principles and how to apply them in basic clinical situations. Therefore, educational initiatives and training programs devised to help them think through common clinical scenarios using Islamic principles would be very useful. Developing practical and clinically relevant tools to assist Muslim families with Islamic perspectives on medical decision-making, such as decision charts, informational materials, and online resources, would also be a great contribution. Muslim physicians interested in bioethics should consider serving on their local hospital's ethics committees, but only after obtaining the appropriate training themselves.

Another crucial element to improving engagement on bioethical issues is to develop relationships, trust, and better communication between medical professionals and Islamic scholars. An extremely useful service would be scholars making themselves available via Islamic bioethics hotlines to provide timely advice and support to clinicians, patients, and families.

No discussion on empowering stakeholders would be complete without mentioning the American Muslim community. Educational initiatives to encourage family members to think about and discuss common bioethical issues (e.g., end-of-life issues) would greatly ease the burden of making such decisions at a patient's bedside. Access to educational websites and to scholars staffing ethics hotlines for questions and support would greatly empower the community.

We should also encourage the development of centers and groups that are willing to take on the challenges of Islamic bioethics study, research, and education. These centers could then serve as referral resources with trained providers who can screen the issues, help with basic advice, and know when to refer the questions to higher-level scholars. Some initiatives in this area are already underway, but most of the work has yet to be done. Our community remains in serious need of these and other such resources. I sincerely appreciate and value the vitally important work being done in this field by Dr. Aasim Padela at the University of Chicago, who is truly a leader and pioneer in these efforts. As an example, he is the director of the university's Initiative on Islam and Medicine. 
I remember the first day of my clinical bioethics fellowship. I walked into the office of Dr. Robert Taylor, who at the time was the director of our academic medical center's clinical consultation service. He is a neurologist, a palliative care physician, and Catholic by faith. He was also my first ethics mentor. What struck me right away was his bulletin board. I would have expected the expansive sheet of cork behind his desk to be covered with notes, articles, and photos. Instead, it was completely bare, except for a single word pinned to it. That word was "courage." This is the concept he chose to keep in his sight as he worked in the field of ethics and end-of-life care.

Practicing clinical bioethics takes courage - the courage to be present and engage, to make a decision that could have life-or-death consequences, to stand and do the right thing, to question if you even know what the right thing to do is, and to challenge when your witness for justice can endanger your comfort, safety, relationships, or position.

I still think about the Muslim woman who called me years ago, whose mother was literally on the verge of death. Could the same type of call come again, or have we gotten to a point where grasping in the dark is no longer necessary? Last year I received a text asking the following question: If a person had had a massive stroke from which recovery was not possible but was breathing on her own, was it Islamically necessary to insert a feeding tube to feed her? A Muslim ethics colleague sitting with me when I received it was surprised that someone would text this query to me because, as she said, "usually people ask the imam this type of question." I informed her that it was the imam who was texting.

At the present time, we are not meeting the American Muslim community's needs in terms of support for making decisions when confronted with biomedical dilemmas. We need to do better. First, we need to end the era in which local religious advisors who lack the appropriate religious scholarship and medical knowledge and training feel comfortable giving complex medical advice. We have been complacent for far too long in allowing this to happen, and this complacency has resulted in immense suffering, moral and physical distress, and the depletion of financial and emotional resources.

We must turn the tide and refocus our efforts. We must uphold the great values of our faith with regards to truth and scholarship, beneficence to humanity, and courage. By intensifying our efforts to merge excellence in religious scholarship with excellence in clinical understanding and then disseminating this information more effectively, we can better help patients and families navigate the religiously sanctioned options in their particular circumstances. Now is the time to make this a priority. 
The Journal of Islamic Faith and Practice // Volume 2, Issue 2

\section{References}

American Academy of Hospice and Palliative Medicine Statement on Artificial Nutrition and Hydration Near the End of Life. Approved by the AAHPM Board of Directors on September 13, 2013. This document was taken from a Web site. Retrieved June 16, 2019. Retrieved from http://aahpm.org/positions/anh

ASBH Core Competencies For Healthcare Ethics Consultation. $2^{\text {nd }}$ ed., (2011).

Eckenwiler, L. A., \& Cohn, F.G. (Eds.). (2007). The ethics of bioethics: Mapping the moral landscape. Baltimore: The Johns Hopkins University Press.

Kipnis, K. (2009). The certified clinical ethics consultant, HEC Forum 21(3), 249-261. 